\title{
ИНДИВИДУАЛЬНО-ЛИЧНОСТНЫЕ ХАРАКТЕРИСТИКИ ПАЦИЕНТОВ С ПОЛИНАРКОМАНИЕЙ В ЗАВИСИМОСТИ ОТ ТЯЖЕСТИ ВЛЕЧЕНИЯ К НАРКОТИКУ
}

\section{INDIVIDUAL AND PERSONAL CHARACTERISTICS OF PATIENTS WITH POLYNARCOTIC ADMINISTRATION DEPENDING ON THE SEVERITY OF DRUG ADDICTION}

\section{Chaar Maalouli Maria}

Summary: The article presents the results of a study of individual and personal indicators in patients with polydrug addiction, depending on the severity of drugs. In the group with a low level of craving for the drug, there is a low level of self-control and instability to frustration. At the same time, the group with a high level of addiction to the drug is distinguished by a lack of criticism of the disease, as well as low selfcontrol and emotional instability. It was found that criticism of the disease is present only in the group with moderate drug cravings. A distinctive feature of this group is a high level of anxiety and a high level of self-control.

Keywords: substance abuse, drug craving, personal traits.

\section{Введение}

$X$ отя опиоидная зависимость считается одним из наиболее распространенных видов наркомании, в последнее время увеличилось количество пациентов с полинаркоманией, которая характеризуется интенсивным течением и патологическим влечением к наркотикам. Таким образом, пациенты с полинаркоманией страдают от физической зависимости и симптомов отмены, и, пытаясь облегчить тяжесть этих симптомов, они прибегают к употреблению любого доступного наркотика в попытке облегчить эти симптомы, в отличие от пациентов с мононаркоманией [3]. Синдром зависимости - комплекс поведенческих, познавательных и физиологических симптомов, который возникает после повторного использования вещества и обычно включает сильное желание принять его. Как видно из представленного определения, стержневым симптомом при любых видах зависимостей является патологическое влечение (ПВ) к наркотику. Ряд исследований показывает, что тяжесть влечения к наркотику, а также особенности проявления данного симптома оказывают значимое влияние на качество ремиссии, а также вероятность рецидива. Согласно C.Y. Su, C.Y. Kung и др., у пациентов с интенсивным влечением к наркотикам наблюдается усиление рецидива [5 с. 58].

\author{
Шаар Маалоули Мария \\ Аспирант, Российский государственный педагогический \\ университет им. А.И. Герцена (Санкт-Петербург) \\ mashashaarmaalouli@yandex.ru
}

Аннотация: В статье представлены результаты исследования индивидуально-личностных особенностей у пациентов с полинаркоманией в зависимости от тяжести влечения к наркотику. В группе с низким уровнем влечения к наркотику установлен низкий уровень самоконтроля и неустойчивость к фрустрации. При этом группа с высоким уровнем влечения к наркотику также характеризуется отсутствием критики к болезни, а также низким самоконтролем и эмоциональной нестабильностью. Установлено, что критика к болезни присутствует только в группе со средней тяжестью влечения к наркотику. Отличительной особенностью данной группы является высокий уровень тревожности и высокий уровень самоконтроля.

Ключевые слова: тяжесть влечения к наркотику, полинаркомания, критика к болезни, индивидуально-личностные особенности.

В настоящее время детально изучены нейрофизиологические и биологические предикторы патологического влечения, однако психологические особенности лиц с различной степенью тяжести влечения к наркотику остаются неизученными [4]. В настоящей работе представлены результаты исследования клинико-психологических особенностей пациентов с полинаркоманиями с различной степенью тяжести влечения к наркотику.

\section{Организашия исследования}

Для оценки патологического влечения и его основных патопсихологических симптомов использовалась клиническая шкала оценки патологического влечения к наркотику Винниковой М.А. [1]. Оценка личностных особенностей осуществлялась с помощью 16-факторного личностного опросника Р. Кеттела. В исследовании принимали участие пациенты с полинаркоманией. Общая выборка составила 33 человека, из них 23 мужчины и 10 женщин. Исследование проводилось на базе Городской наркологической больницы, Межрегиональной благотворительной общественной организации «Благодать» и Городской психиатрической больницы № 3 имени И.И. Скворцова-Степанова в г. Санкт Петербург. В зависимости от тяжести влечения к наркотику все паци- 
енты были разбиты на три группы: пациенты с низким влечением к наркотику ( $\mathrm{n}=12, \mathrm{M}=11$, ж=1, средний возраст=34.5, длительность ремиссии=36 дней), средним уровнем влечения к наркотику $(n=11, \mathrm{M}=11, ж=0$, средний возраст=35.5, длительность ремиссии $=32$ дня), высоким уровнем влечения к наркотику $(n=10, \mathrm{~m}=9, *=1$, средний возраст=30, длительность ремиссии=36 дней). Для статистического анализа различий использовался критерий Краскелла-Уоллиса.

\section{Результаты исследования}

Пациенты с полинаркозависимостью, вошедшие в группу с низким уровнем патологического влечения, характеризуются отсутствием навязчивых мыслей о наркотиках, достаточно стабильным эмоциональным состоянием. Анализ критики к болезни и готовности к терапии показывает преобладание частичной критики к болезни у пациентов. Установка на лечение носит формальный или формально-вынужденный характер.

Анализ индивидуально-личностных характеристик показал, что данная группа пациентов характеризуется высоким уровнем общительности и коммуникабельности. При этом эмоциональная сфера характеризуется неустойчивостью планов и интересов, низким самоконтролем, низкой толерантностью к фрустрирующим событиям. Выявлены низкие показатели нормативности и ответственности, склонность нарушать принятые правила. Выявлены смелость и готовность к риску, а также конформизм. Зависимость пациентов от мнения окружающих и значимость социальных контактов может значительно снижать риски рецидивов. В тоже время пребывания в патологической среде может повышать риски срывов. Отсутствие в данной группе пациентов явных признаков абстиненции в сочетании с формальной критикой к лечению может создавать иллюзию ремиссии как для самих пациентов, так и для специалистов, сопровождающих процесс реабилитации. В связи с этим данная группа пациентов нуждается в дополнительной психологической коррекции, направленной на формирование критики к своему состоянию и комплаенса.

Пациенты с полинаркозависимостью, вошедшие в группу со средним уровнем патологического влечения к наркотику, характеризуются периодически возникающими мыслями о наркотиках, аффективными нарушени- ями в виде тревожности, проявляющейся в нервозности, напряженности, неспособности расслабиться. При этом критика к болезни стабильная и полная. Пациентам группы со средним уровнем патологического влечения к наркотикам свойственны: замкнутость и необщительность, податливость в социальных контактах и застенчивость. Пациенты демонстрируют эмоциональную стабильность, им не свойственны резкие перепады настроения, но при этом они не соответствуют характеристикам эмоционально-ригидной личности. Также пациенты данной группы характеризуются высокими показателями интроверсии и трудностями в установлении социальных контактов и межличностного взаимодействия.

Пациенты, вошедшие в группу с высоким уровнем патологического влечения к наркотику, характеризуются постоянным присутствием обсессивных идей и мыслями о наркотиках. У большинства пациентов отсутствует критика к болезни, либо она носит формальный характер. Анализ индивидуально-личностных особенностей пациентов с высоким уровнем патологического влечения к наркотическим веществам определил склонность к замкнутости и отчужденности, эмоциональной нестабильности. Также наблюдается склонность к пренебрежению социальными нормами, низкий контроль собственного поведения. Показатели тревожности в данной группе низкие.

\section{Зак^ючение}

Таким образом, сравнительный анализ групп с низким, средним и высоким уровнем влечения к наркотику характеризуется различиями в индивидуально-личностных особенностях. Как пациенты с низким уровнем влечения к наркотику, так и пациенты с высоким уровнем влечения к наркотику, обе группы характеризуются отсутствием критики к болезни и низким самоконтролем. То есть, несмотря на отсутствие физиологических признаков влечения к наркотику, у пациентов с низким уровнем влечения существует риск рецидива. Анализ группы со средним уровнем влечения к наркотику показал высокий уровень тревоги и критики к болезни, что может указывать на ключевую роль тревожности в осознании необходимости терапии.

Конфликт интересов отсутствует.

\section{ЛИТЕРАТУРА}

1. Винникова М.А. Ремиссии при героиновой наркомании (клиника, этапы течения, профилактика рецидивов): дис. мед. Наук /Винникова Мария Алексеевна. - М., 2004. -243 с.

2. Доклады Международного комитета по контролю над наркотиками за 2019 год // www.incb.org URL: https://www.incb.org/documents/Publications/ AnnualReports/AR2019/Annual_Report/Russian_ebook_AR2019.pdf.

3. Кулаков С.А. Психотерапевтический диагноз в реабилитации пациентов, зависимых от психоактивных веществ /С.А. Кулаков //Наркология. 2013. - 


\section{Т. 12. - № 9 (141). - С. $85-90$.}

4. Менделевич, В.Д. Аддиктивное влечение: теоретико-феноменологическая оценка / В.Д. Менделевич. //Наркология. - 2010. - № 5. - с. 94-100.

5. Su C.Y. et al. 146 A Study of Relationship among Drug-used Impulsivity, Beliefs and Craving, and Intention to Relapse on Drug Addicts // Asian Journal of Psychiatry. - 2011. - 4. - P. S58.

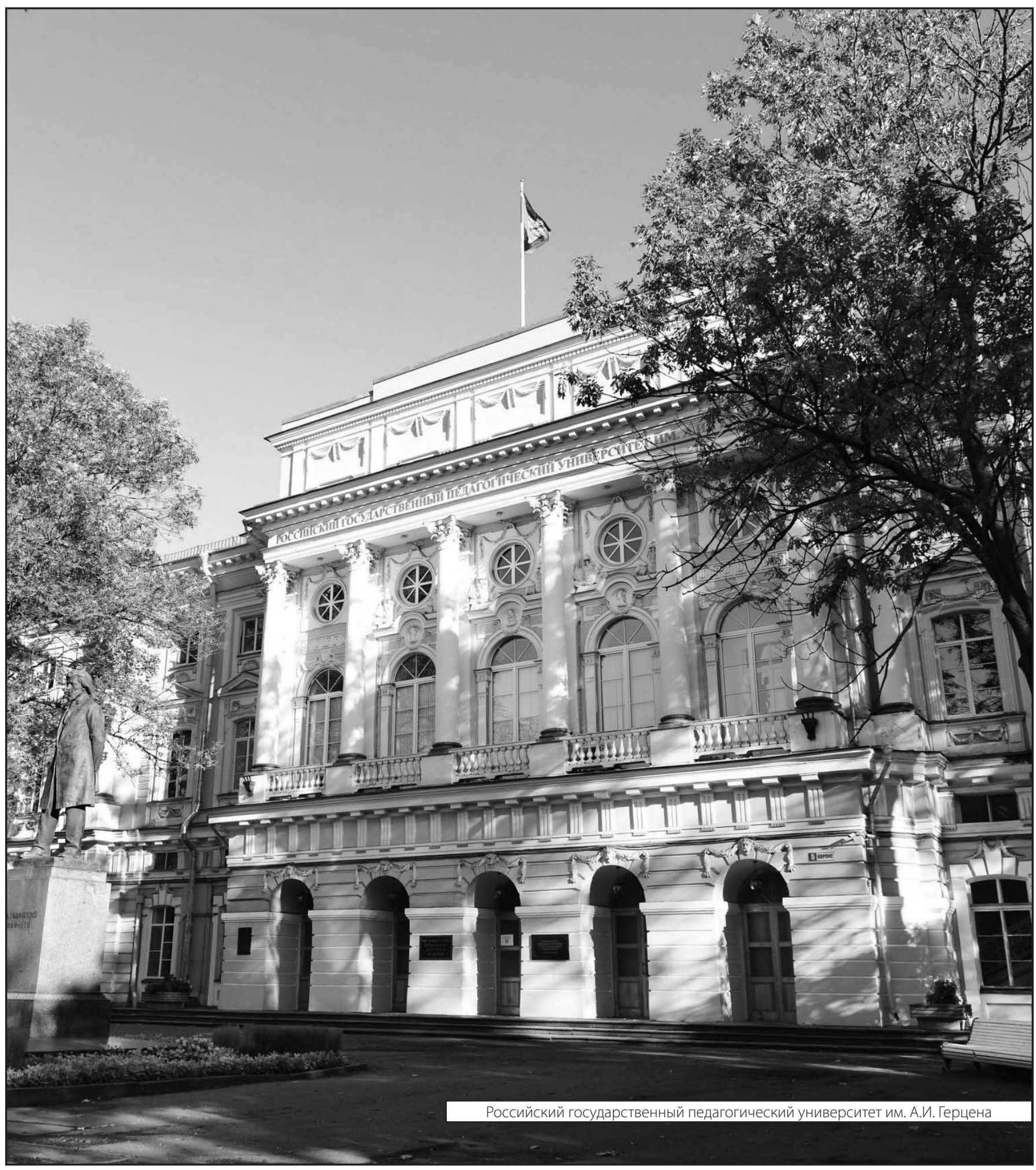

